\title{
Educational policy to improve mathematics instruction at scale: conceptualizing contextual factors
}

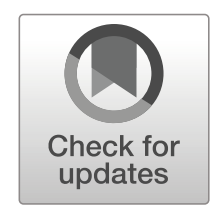

\author{
Andreas Ryve ${ }^{1,2}$ (D) Kirsti Hemmi ${ }^{3,4}$
}

Published online: 15 March 2019

(C) The Author(s) 2019

\begin{abstract}
Theories for conceptualizing educational policies aimed at improving classroom instruction at scale are under development in the educational sciences. In using such theories, it is essential to note the specific educational context. In this article, we conceptualize the role of contextual factors when operationalizing Cobb and Jackson (2012) [Journal of the Learning Sciences] in the Swedish context. Drawing on data and results from a large-scale project carried out during 2012-2017 and studies of Swedish educational contexts, we conceptualize contextual factors for large-scale projects. Besides rather obvious explicit contextual factors such as ongoing policies and practices, we elaborate on how the underlying, more implicit contextual factors of (1) the positioning of teachers within the educational system, (2) the positioning of teachers within the classroom, and (3) traditions of visible and invisible pedagogy affected the establishment of policy in the Swedish context. Insight into these factors deepens earlier frameworks of context, and helps not only to operationalize the policy within the context but also to make explicit hidden features of a cultural context that are important to influence if the aim of the educational policy is to reorganize school practices.
\end{abstract}

Keywords Educational context · Educational policies at scale $\cdot$ Mathematics education . Professional development $\cdot$ Classroom practices

Andreas Ryve

andreas.ryve@mdh.se

Kirsti Hemmi

khemmi@abo.fi

1 Mälardalen University, 72220 Västerås, Sweden

2 Østfold University College, 1783 Halden, Norway

3 Åbo Akademi University, Turku, Finland

4 Uppsala University, Uppsala, Sweden 


\section{Introduction}

Theories and frameworks for conceptualizing and implementing educational policies on local levels (Smith \& Stein, 2011; Ruthven, Laborde, Leach, \& Tiberghien, 2009) and on a large scale (Cobb \& Jackson, 2012; Desimone, 2009) are receiving considerable attention within educational research. The nature of these theories and frameworks is dependent upon, and interrelated with, assumptions about policies, perspectives on implementation, and the positioning of those affected by the policies (Fullan, 2001). In addition, and importantly, research stresses that theories that are used to guide interventions and policies must be operationalized in relation to context (Bryk, Gomez, Grunow, \& LeMahieu, 2015; Cobb \& Jackson, 2012). However, while it is relatively straightforward to acknowledge that context matters, it is far from obvious to specify which contextual factors are central and how they affect the operationalization of the policy.

While the idea that contexts affect the enactment of curriculum materials (Remillard, 2005), professional development programs (Desimone, 2009) and educational policy (Cobb \& Jackson, 2012) is not new, it is undertheorized (Century \& Cassata, 2016). Recent educational research (Century \& Cassata, 2016) introduces contextual factors such as characteristics of the individual teacher (knowledge, experiences, beliefs, values) and the organization (class size, physical space, organizational administration, collective attitudes) as essential. Similar ideas exist in professional development research, where programs are to be coherent with teachers' beliefs and practices as well as with organizational aspects such as standards, policies, assessments, and curricula (Desimone, 2009). In small-scale studies, it seems appropriate and feasible to consider the contextual factors of each individual teacher, each classroom and each organization. However, in improving instruction at scale, researchers typically work with hundreds of teachers and many school organizations, making it necessary to take another approach to context. Instead of examining each individual, classroom, and organization, it is necessary to build on research capturing more general patterns in the current contexts.

In addition, seeking general patterns of teacher characteristics, ongoing practices, and organizations is necessary but not sufficient. That is, more hidden and implicit characteristics of context, such as the positioning of teachers within practices and in relation to policy, are essential (Remillard, 2005). Such contextual factors are touched upon in the literature on largescale educational policy by, for instance, Bryk et al. (2015) and McClain, Zhao, Visnovska, and Bowen (2009). We aim to contribute to research on such implicit contextual factors and how to take them into consideration in improving mathematics instruction at scale. We do this by theorizing the operationalization process of the framework by Cobb and Jackson (2012) within the cultural-educational context of Sweden, and our goal is to contribute to international research on how to conceptualize context to improve instruction at scale (Bryk et al., 2015; Century \& Cassata, 2016; Cobb \& Jackson, 2012).

Below, we first introduce the educational policy of Count on Västerås $(\mathrm{CoV})$, a researchbased project aimed at improving mathematics instruction at scale (2012-2017). We then elaborate on three contextual factors, exemplify them within the Swedish context, and argue why it is essential to consider them in the design and establishment of educational policy at scale. Finally, we discuss these contextual factors and their significance for understanding and designing large-scale projects in diverse contexts.

This is a reflective article in which we draw upon our own empirical studies of the project, studies of the Swedish context, international research, and several years of close collaboration with schools to make our claims. As such, our elaboration on this large-scale educational 
policy in Sweden is based on theoretical considerations and empirical evidence and aims to conceptualize contextual factors.

\section{Count on Västerås-the project}

Below, we introduce the basic facts, main principles and essential positions, learning events, routines, and tools of the policy. This presentation aims to give the reader an overview of the project that, in turn, can help in understanding the elaboration on how contextual factors affected the operationalization of the policy.

The Count on Västerås $(\mathrm{CoV})$ project was carried out in close collaboration between actors within one large municipality in Sweden and the research group at the University of Mälardalen, Sweden. The research budget was approximately 2 million Euro, while the development project was much more encompassing. During 2012-2017, we worked together with the municipality to plan, implement, and evaluate an educational policy with the final aim of creating opportunities for students to develop mathematical proficiency (cf. Kilpatrick, Swafford, \& Findell, 2001) through the development and reorganization of mathematical classroom practices. Central aspects of high-quality classroom practices envisioned in the project include a focus on strands of mathematical proficiency, cognitive demand, the engagement of all students in activities, productive norms, and student-centered and teacherorchestrated practices (Ryve, Hemmi, \& Kornhall, 2016). To, in turn, develop mathematical classroom practices, we worked with seven to nine schools each year for five years (in total 38 schools, about 400 teachers and 10,000 students). Without going into detail here, the project was largely highly appreciated within the municipality and contributed to the development of mathematics teaching and an improvement of students' results there (see also Lindvall, 2017a, 2017b; Lindvall, Helenius, \& Wiberg, 2018).

\subsection{Theoretical basis of CoV}

The theoretical basis on policy for CoV stems from Cobb and Jackson's (2012) learning design perspective. Firstly, the perspective emphasizes that the implementation of policies includes an active sense-making of agents such as teachers, coaches, and principals (cf. Lloyd, Remillard, \& Herbel-Eisenmann, 2009). Secondly, we assume that policy implementation requires changes to practices rather than solely the support of those that are already prevalent. Hence, $\mathrm{CoV}$ aimed to support the reorganization of practices, which, in turn, requires actors' learning. Thirdly, from a learning design perspective, the implementation was to be conceptualized as instruction and therefore also include support for the actors' learning. The support for learning, improvement and reorganization in $\mathrm{CoV}$ was realized through new positions, new learning events, new organizational routines and new tools (Cobb \& Jackson, 2012).

\subsection{New positions, new learning events, new organizational routines, and new tools of $\mathrm{CoV}$}

New positions refers to both changes to the responsibility of already established positions and the introduction of new positions within organizations. In CoV, Heads of Mathematics (HMs) at each school were established, and given the Swedish context, three missions were negotiated: arrange collective participation; collaborate with principals in structural processes of 
analyzing students' learning progression in mathematics; and keep track of research and development work in Sweden to inform colleagues. Further, we also established the new position of Mathematics Mentors (MMs), who worked $40 \%$ of their time in the municipality and engaged in $\mathrm{PhD}$ studies at the university for the remaining $60 \%$. Within the municipality the three MMs held a key position in implementing new learning events with teachers around mathematics instruction, as they participated in the program design and served as leaders of the learning events at each school. As such, the MMs served as important actors in establishing the policy and as boundary breakers between university and municipality.

Teachers' professional development is a common feature of educational policies, and a typical example of what Cobb and Jackson (2012) refer to as a new learning event. Within $\mathrm{CoV}$, a research-based professional development program for teachers constituted a central part of the policy. This was realized through 19 two-hour collegial meetings at each school throughout the school year. Throughout these meetings, the teachers were actively engaged, together with their colleagues, in planning, implementing, and reflecting upon mathematics instruction (see further below and Lindvall, 2017b). Basically, we aimed to enact Desimone's (2009) five critical features of active learning, collective participation, duration, coherence, and content focus in designing the PD and learning events (see Lindvall et al., 2018). As mentioned above, the MMs were responsible for these events, and in turn $\mathrm{CoV}$ arranged learning events to allow the teachers to become more comfortable and effective in their role.

As a complement to the work with the teachers, we designed a professional development program for HMs during 2013-2014 and a program for principals and HMs during 20142015. The professional program for the $60 \mathrm{HMs}$ consisted of five 3-h meetings at which we introduced theories on group processes, coaching techniques, and a number of tools to support the HMs in planning and leading collegial discussions. The professional development program for principals and HMs during 2014-2015 encompassed five meetings totaling 14 h. 40 principals and $60 \mathrm{HMs}$ participated in the program, of which the main aim was to support them in establishing new routines, new tools, new learning events, and new positions in order to work systematically in developing mathematics instruction through, on a large scale, collecting and analyzing data on students' knowledge in mathematics. This formal learning event for the HMs and principals served as a starting point for more informal and incidental learning events at each school (cf. Cobb \& Jackson, 2012).

The establishment of new organizational routines was also an important part of CoV. Organizational routines are repetitive patterns of independent actions carried out by multiple actors (Feldman \& Pentland, 2003), and such routines connected to teachers' work are receiving more attention within the educational literature (Franke, Kazemi, \& Battey, 2007). We initiated many new organizational routines, such as working with cognitively demanding tasks in the classroom (cf. Smith \& Stein, 2011), routines to reassure that mathematics teachers and HMs meet regularly to discuss the goals and content of mathematics teaching, and routines for how schools summarize results from tests and use them to analyze and develop the organization of the schooling (Håkansson, 2013).

Finally, some new tools were introduced, designed, and established. Here, tools are material entities included in processes to accomplish specific goals, and are typically central components of educational policies (Borko, 2004). From a sociocultural perspective (e.g., Wertsch, 2007), individuals' appropriation of tools is central in thinking and acting in social practices. Tools are not simply designed to support learning and reorganizing practices; in large-scale projects, they also function as means to support, for instance, different teachers in establishing compatible practices, and to align the practices of actors from different role groups (Cobb \& 
Jackson, 2012). In learning events with teachers, CoV introduced tools with the primary purpose of supporting participants' learning, such as the use of students' solutions to mathematical problems (Kazemi \& Franke, 2004) or video-recordings of classroom teaching (Ball, Sleep, Boerst, \& Bass, 2009). Also, tools intended for use in classroom practices, such as cognitively demanding tasks or frameworks of teachers' questions and moves (see Smith \& Stein, 2011), were introduced.

\subsection{Methodology of CoV}

We used educational design research (McKenney \& Reeves, 2012) to engage in the processes of designing, operationalizing, establishing, and analyzing the learning design theory (Cobb \& Jackson, 2012). These processes were carried out in an iterative manner from both a micro-perspective each month and a macro-perspective each year (cf. Cobb, Stephan, McClain, \& Gravemeijer, 2001). The program theory of Desimone (2009), focusing on the professional development initiative, teachers' views and competences, classroom instruction, and students' mathematical knowing, served as the basis for developing a methodology for measuring, analyzing and developing practices and tools. Therefore, we established a program for collecting and analyzing data encompassing numerous sources. Firstly, we used a large questionnaire for all 400 teachers who were teaching mathematics within the municipality in 2012 (e.g., Neuman Lindvall, Hemmi, Ryve, \& Wiberg, 2015) to capture their views on the support from ongoing PD in the municipality and on productive classroom practices. Secondly, we used rather encompassing pre-, midterm- and post-questionnaires for all teachers participating that school year (see Lindvall, 2017a) to capture their views on their classroom practices, multiple aspects of the PD, their students, and the support they received from the principals. Thirdly, we distributed and analyzed tests to measure the mathematical knowledge development of all students within the municipality each year (e.g., Lindvall, 2017b; Lindvall et al., 2018). Fourthly, we carried out several studies of dominating textbooks and teacher guides in the Swedish context (see references below), to examine the views of the curriculum programs on productive classroom practices and the support for teachers in planning and enacting classroom teaching. Finally, we conducted interviews with Swedish teachers and teacher educators-reported in, for instance, Ryve, Hemmi, and Börjesson (2013) and Hemmi and Ryve (2015a) - to capture discourses on teachers and classroom practices in Sweden. For each study, we have outlined the methodology, data and method of analysis in the publications specified. In this article, we use the results from these studies to elaborate on implicit contextual factors and how they affected the operationalization of Cobb and Jackson (2012) in the Swedish context.

\section{Contextual factors influencing the design and enactment of CoV}

Based on the data, results and publications of our research group, other studies from the Swedish context (e.g., Boesen et al., 2014), research on professional development and educational policies (e.g., Desimone, 2009; Fullan, 2001), and theories on the positioning of teachers within the educational context (e.g., Bernstein, 2000; Porter, Archbald, \& Tyree Jr., 1990), we elaborate on how contextual factors influenced the design and enactment of CoV. 


\subsection{The positioning of teachers within the educational system}

Throughout the project, we became more aware of, and adjusted the program in relation to, the positioning of teachers within the educational system. Research shows that traditional Swedish national educational policy can productively be characterized by positioning it on a continuum of empowerment and control (Hemmi \& Berg, 2012). The policy of control is typically exercised through detailed syllabi, curriculum materials, and standardized tests and exams that the schools and teachers are obligated to use, while the policy of empowerment refers to teachers' autonomy as well as various strategies for supporting teacher professionalism. In the Swedish case, the policy of empowerment has dominated, and this has influenced the power relations between the various actors at different levels of the educational system (national agencies, researchers, municipalities, principals, and teachers) (Hemmi \& Berg, 2012). For example, the Swedish national policy documents leave a great deal of space for teachers to apply them in their own ways; and the current Swedish national syllabus, implemented when this project began, can only be considered a framework as it does not suggest textbook materials or teaching methods, lesson plans or tests.

Therefore, in designing new learning events, we did not "implement" a fixed "professional program" holding variables constant (cf. McClain et al., 2009), but instead made explicit that teachers both actively participated in the learning event and had substantial opportunities to influence the program's realization. In addition, the designed tasks, frameworks, and question batteries focused on teachers' attention to critical aspects of planning, establishing and reflecting upon classroom teaching, but did not prescribe actions (cf. Ruthven et al., 2009) without specifying an explicit rationale for the teaching practices (Kennedy, 2016). That is, there are different perspectives within educational research on how the receiver, often the teacher, is positioned in relation to the intervention (e.g., Kennedy, 2016; McClain et al., 2009; Remillard, 2005). It was also necessary for $\mathrm{CoV}$ to consider the empowerment culture in Sweden (Hemmi \& Berg, 2012) in designing new learning events in which teachers had agency in influencing aspects of these events.

Further, we did not follow Cobb and Jackson (2012) in, for instance, establishing "learning walks" in which mathematics coaches and principals visit and observe teachers' classrooms, since such walks stand in stark contrast to the positioning of teachers in the Swedish educational system - in Sweden, coaches and principals should empower teachers, and learning walks were seen by the municipality leaders as a new routine that controlled more than empowered teachers. Nevertheless, principals' work is highlighted in policy documents as crucial in establishing and maintaining effective schools in Sweden. The role of the principal is to empower teachers in developing classroom teaching through systematic analyses of students' results, rather than in terms of controlling the teachers' instruction (Ryve et al., 2016). However, studies show that the competence, routines, and tools for carrying out this work are typically weakly developed in Sweden (Håkansson, 2013). Consequently, we initiated and supported the organizational routine of distributing, correcting and summarizing the students' results on large-scale tests, serving as a starting point for analyzing and establishing improvement initiatives that are subsequently measured and evaluated. The support for establishing this new organizational routine includes both new learning events and new tools designed for use in practice. Importantly, and related to the empowerment-control dimension, in summarizing and analyzing large-scale tests such as the Swedish national tests we were explicit about not controlling the individual teachers, but rather using the results as formative instruments for all actors to reorganize the practice. 
The establishment of new roles was also dependent upon the relationship between teachers and other actors within the educational system. For instance, in establishing HMs we came across the idea that it is problematic to regard certain teachers as better than others by giving them, for instance, the mandate to serve as experts in interaction among colleagues. During the project, this perspective became apparent in many instances related to, for example, the government's initiatives to establish "first-teacher positions" (Kornhall, 2015), the complications and hesitation involved in correlating students' results in mathematics with individual teachers within the municipality, and skepticism among teachers regarding listening to "bestpractice teachers." Therefore, rather than serving as experts during collective participation, as suggested in the US context (cf. Coburn \& Russell, 2008), the mission, tools, and professional development of the new position of HM were designed to support them in preparing and organizing collective participation among teachers.

Finally, as teachers' agency is strong in Sweden and professional development programs and tools are typically used to empower them on the one hand, and classroom teaching in Sweden is often characterized by a reactive teacher (Hemmi \& Ryve, 2015a) on the otherand we wanted to change this, as described below-we struggled to develop and introduce tools that empower teachers by making their work explicit. That is, we aimed for tools that blend the talk to the teacher (Remillard, 2000) to educate them (Davis \& Krajcik, 2005) in a general manner and tools talking through the teacher (Remillard, 2000), as a way to steer and support their actions in the classroom. In other words, there is a fine balance between aiming to reorganize classroom practice and empowering teachers by introducing new tools, new routines, and new positions.

To sum up, in designing and establishing new learning events, new routines, new positions, and new tools, we became aware of the positioning of teachers in the educational system and adjusted the program based on this contextual factor. As further discussed below, to a considerable extent, we did not aim to challenge or change this contextual factor but instead reinterpreted how it should affect the operationalization of practices and tools.

\subsection{The positioning of teachers within the classroom}

Within $\mathrm{CoV}$, we assumed that for classroom practices to be productive for students' development of mathematical proficiency, both students and teachers need to be active (Brodie, 2011). By an active teacher we mean one who is active in, for instance, setting goals, introducing mathematical content, challenging students' thinking, orchestrating classroom discussions, and supporting students' autonomy. In contrast, our analyses of discourses on effective classroom teaching in mathematics among teachers and teacher educators in Sweden (Hemmi \& Ryve, 2015a) show that they are positioned as rather passive when it comes to such practices. For instance, an illustrative example comes from Hemmi and Ryve (2015a), in which a teacher educator comments on a mathematics lesson he/she has just observed:

This was a very typical lesson, like many others look like. You (the teacher) walk around, you do not have to say that this is not good, because it's good. You walk around and that's actually the teacher's work. You walk around and listen to the students, they raise their hands, they ask, you try to listen, what's the problem, how are we to approach this problem". (p. 508)

Hence, as the extract above suggests, Swedish teachers act reactively rather than proactively in the mathematics classroom. To support teachers in broadening their arsenal of instructional 
moves, we designed and implemented new learning events to support and reposition them as active in anticipating students' mathematical thinking, setting learning goals, assessing and giving feedback to students, explaining mathematical ideas, and orchestrating whole-class discussions (Smith \& Stein, 2011).

Our decision to focus on supporting teachers in actively engaging in classroom practices to create opportunities for students to develop conceptual understanding and mathematical problem-solving competencies was also anchored in studies on characteristics of Swedish mathematics textbooks and teacher guides, and on how teachers' work in the classroom is portrayed (e.g., Brehmer, Ryve, \& Van Steenbrugge, 2016; Hemmi, Koljonen, Hoelgaard, Ahl, \& Ryve, 2014). That is, our analyses show that dominating curriculum programs give students few opportunities to develop conceptual understanding and problem-solving, and that teachers are positioned as rather passive in the classroom practice (Brehmer et al., 2016; Remillard, Van Steenbrugge, \& Bergqvist, 2014). For instance, Brehmer et al. (2016) conclude that the "content of the textbooks themselves does not fulfil the formulations according to MPS [Mathematical problem-solving] as presented in the national policy documents" and that "in the current situation in Sweden a heavy responsibility lies on the teacher to provide students with opportunities to engage in MPS" (p. 589). In other words, current support from textbooks and teacher guides concerning both types of tasks and the support for teachers to act in the classroom, together with discourses in Sweden on the positioning of teachers in the classroom (Hemmi \& Ryve, 2015a), strongly influenced how new learning events, new tools, new routines, and new positions were designed.

To sum up, in aiming to create opportunities for students to develop strategic competences and conceptual understanding, it is essential to consider the characteristics of classroom practices. In relation to the Swedish context, the positioning and role of teachers in these practices were central in designing and implementing the policy. The positioning of the teacher in the classroom - both as it currently was and as we envisioned it - strongly influenced the educational policy. Here, and in contrast to the contextual factor of the positioning in the educational system, we deliberately aimed to challenge and change the contextual factor of teachers' positioning in classroom practices. For finding ways to do this, the framework by Cobb and Jackson (2012) was useful, as further discussed at the end of this article.

\subsection{Traditions of visible and invisible pedagogy}

In parallel to the planning of $\mathrm{CoV}$, we analyzed the Swedish educational context with the help of Bernstein's (1990, 2000) theories, and the concept of invisible pedagogy was useful for understanding the education context of Sweden. Invisible pedagogy is connected to the two concepts of weak classification and weak framing (Bernstein, 1990, 2000). Classification refers to the boundaries between different mathematical contexts within the subject and the relations between mathematics and other subjects, as well as everyday practices. Framing concerns the control of communication in local interactional pedagogic relations. This control can be over the selection of the communication along with its sequencing and pacing, as well as the criteria or the assessment (Bernstein, 2000). The pedagogic practice in Swedish mathematics classrooms has been relatively weakly classified and framed during the past two decades (cf. Hemmi \& Berg, 2012). For example, before the curriculum reform in 2011, only very general goals for the fifth and ninth grades in compulsory school were presented. The current Swedish national curriculum can be regarded as only a general frame (Hemmi, Lepik, \& Viholainen, 2013). In addition, the boundaries between mathematics as a discipline 
on the one hand and students' everyday life on the other have been weakened due to mainstream pedagogical trends advocating strong connections to everyday life. Hence, the Swedish context could productively be understood in relation to visible-invisible pedagogy (Hemmi \& Berg, 2012). Bernstein (2000) portrays aspects such as implicit rather than explicit control over students, reduced focus on acquisition of skills, free activities of students, and the use of diffuse criteria for evaluating education as typical of invisible pedagogy. In Sweden, the integration of different school subjects as well as the emphasis on students' free choice regarding their learning activities and their rate of learning have been dominant (Ryve et al., 2016) and connected to invisible pedagogies (e.g., Bernstein, 2000; Fowler \& Poetter, 2004). The strong emphasis on students' motivational aspects and the child's right to develop at his/ her own rate in the Swedish context also indicates invisible pedagogies (Hemmi \& Berg, 2012).

Aspects of invisible pedagogies also surfaced in other studies of our research group, as well as in earlier minor school improvement policies and teacher education. Regarding teacher education, our studies show that lesson plans or plans for a longer period used in school-based teacher education are uncommon (Hemmi \& Ryve, 2015a; Ryve et al., 2013). Moreover, since the early 1990s, teachers' work has been organized in "working teams" structured around students rather than the subject they teach, in the sense that teachers teaching the same students meet regularly (Blossing, 2008), a practice that has contributed to an invisibility of mathematics in the school curriculum. Hence, aspects of invisible pedagogy in the Swedish context included a lack of possibilities for teachers to collaborate on mathematics instruction (Blossing, 2008), weak teacher support in curriculum materials (Remillard et al., 2014), and little focus on teacher education in teaching specific subjects (Ryve et al., 2013).

We aimed to strengthen certain aspects of the invisible pedagogy, such as the active engagement of students in the learning process, while at the same time making the pedagogy more visible through making explicit the important work of teachers in the classroom and a more visible use of existing assessment tools (national examinations, tests conducted by the municipality - number sense) through collegial discussions at both the school and municipality levels. Examples are given below.

Within the learning events, we used tools such as the Five Practice Model (FPM) by Smith and Stein (2011) to make explicit pedagogy and the work of teachers. The FPM focuses on the proactive work of teachers, which seemed to be important considering the discourse on effective teaching in Sweden (Hemmi \& Ryve, 2015a) and the invisible pedagogy of Sweden (Hemmi \& Berg, 2012). In other words, we aimed to empower and reposition the teachers as active through making the pedagogy visible, and our data suggest that they appreciated such tools. That is, throughout the first four rounds of pre- and post-questionnaires, of the 254 teachers who completed the post-questionnaire 85-95\% (depending on model and framework) expressed that they appreciated or strongly appreciated tools that support the proactive work of teachers (see Lindvall, 2017b for information about methodology). Importantly, Smith and Stein's model should not be seen as an isolated tool but rather as part of a web of tools supporting teachers' reorganization of practice. The need to introduce a web of tools serving as resources for teachers stems from the Swedish context, in that textbooks and teacher guides provide them with little support in planning, establishing and reflecting more broadly upon classroom teaching and education (e.g., Hemmi, Koljonen, Hoelgaard, Ahl, \& Ryve, 2014; Remillard et al., 2014), as mentioned above. That is, due to the discourse on reactive teachers and weak support in teacher guides, it was necessary to design and establish visible and explicit frameworks and tools to serve as resources for teachers in making year plans and 
lesson plans, establishing formative assessment practices, discussing problem-solving with colleagues, analyzing textbooks, etc.

Further, textbooks are used extensively in Swedish mathematics classrooms (Boesen et al., 2014). At the same time, teachers' use of (and dependence on) textbooks has been conceptualized in highly negative terms in the past 20 years (Ryve et al., 2016). In addition, the tradition of invisible pedagogy is strongly manifested in teacher guides, which are both very brief and non-explicit in supporting teachers in how to act in planning and enacting mathematics teaching, as explained above (Ryve et al., 2016). Interestingly, when analyzing Swedish textbooks and teacher guides, it turned out impossible to identify lessons (Remillard et al., 2014). This could also be considered a sign of the invisible pedagogy of Sweden, as it implies weaker framing. The problematic situation between textbooks and teachers was expressed many times in diverse ways during the project. At the beginning of the project, teachers were hesitant to discuss textbooks and how they were used in teaching. The complex relationship between teachers and textbooks is captured in this statement by one of the teachers: "I must admit that I'm textbook-addicted" (see Ryve et al., 2016, p. 209). Therefore, we had to navigate how to position textbooks and teacher guides within the policy of CoV.

We decided to make the textbooks and teacher guides explicit aspects of the new learning events, in that we analyzed, related to, and made the textbooks an integral part of what it means to plan, establish and reflect upon mathematics teaching. This was one of several ways of making the pedagogy more visible (Bernstein, 1990), by both making explicit the use of textbooks and using this to further stimulate collegial discussions about material, classroom practices, goals, assessment, the nature of mathematics, etc. (Hemmi, Krzywacki, \& Liljekvist, 2018).

To sum up, we aimed to challenge parts of the Swedish invisible pedagogy tradition by introducing new tools and frameworks to discuss assessments, focus on teacher work, analyze dominating textbooks, and make explicit practices of teaching mathematics through problemsolving.

\section{Discussion and conclusion}

In this article, we have conceptualized the contextual factors essential to take into account when establishing new learning events, new routines, new positions, and new tools in a largescale educational policy in Sweden. In large-scale initiatives, it is necessary to approach explicit contextual factors such as characteristics of teachers, classrooms, and organizations (Century \& Cassata, 2016) differently than in small-scale studies. We therefore had to conceptualize national patterns of teacher knowledge, classrooms, and organizational structures (e.g., Ryve et al., 2016) rather than looking at the characteristics of specific teachers, classrooms, and organizations, which is feasible in small-scale studies. Further, besides understanding these explicit contextual factors, large-scale research begins to acknowledge and conceptualize the impact of more hidden and implicit contextual factors (e.g., Bryk et al., 2015; McClain et al., 2009). Three such contextual factors are central to understanding the design and establishment of the educational policy of $\mathrm{CoV}$ : the positioning of teachers within the educational system; the positioning of teachers within the classroom; and traditions of visible and invisible pedagogy. As in the work of McClain et al. (2009) on teachers' professional status, the positioning of teachers comes to be central. In the case of Sweden, we found it interesting that the positioning of teachers within the educational system is strong 
while their positioning in the classroom is characterized as reactive and passive in terms of setting goals, orchestrating classroom discussions, and introducing new mathematical concepts. These characteristics of the positioning of teachers, together with the tradition of invisible pedagogy and ongoing practices, strongly influenced how we designed and iteratively developed the educational policy of CoV. For instance, in designing and working together with teachers in professional development programs throughout the years, choices and emphases were context-dependent. Firstly, with thought to the Swedish empowerment culture (Hemmi \& Berg, 2012), we designed PD in which teachers had agency in influencing aspects of the learning event as well as introduced tools that sensitized teachers to certain aspects rather than prescribing actions. Secondly, we designed and implemented learning events to support and reposition teachers as active in anticipating students' mathematical thinking, setting learning goals, assessing and giving feedback to students, explaining mathematical ideas, and orchestrating whole-class discussions. Thirdly, to support teachers in being active, we introduced numerous frameworks, tools, and assessments to make pedagogy visible. However, we would like to emphasize that our conceptualization of contextual factor and different ways of interpreting consequences of these factors grew throughout the iterative design, establishment, and evaluation of the project.

Further, once conceptualized, we aimed to strengthen the empowerment in the Swedish context, challenge the positioning of teachers in the classroom, and adjust to and complement the prevailing context of invisible pedagogy. In the process of not only relating to the contextual factors but also reinterpreting and challenging them, the learning design perspective and the four strands of new learning events, new routines, new positions, and new tools were very helpful. Below, we first discuss how the contextual factors are interrelated and possible to interpret in diverse ways, and then how the framework by Cobb and Jackson (2012) was adjusted in relation to the contextual factors as well as how the learning design perspective could be used to challenge prevailing contextual factors.

The three contextual factors are neither totally disjunct nor simply related to each other. Rather, they often interact and all three affect individual practices and tools. In addition, the operationalization of specific practices and tools is strongly dependent on how these factors are interpreted. Contextual factors and mathematics textbooks in the Swedish context serve as an illustrative example (see also Van Steenbrugge \& Ryve, 2018). The characteristics of the textbooks and teacher guides, as well as teachers' complex relationship with them, are related to the contextual factor of the teacher's positioning in the educational system. That is, within the empowerment culture in Sweden, textbooks should in no way control teachers. This has resulted in textbooks and teacher guides in which the work of teachers is considerably absent. Despite this, as illustrated above, teachers use textbooks extensively but often feel ashamed to admit it. In contrast, our interpretation of empowering teachers implies the development and introduction of tools, frameworks, and routines that emphasize the work of teachers, as explained above. Hence, our interpretation of the empowerment context implies radically diverse types of support for teachers, compared to how textbook authors and commercial publishers have interpreted this contextual factor. Further, the absence of lessons in the textbooks and teacher guides (Remillard et al., 2014) is an expression of the invisible pedagogy of Sweden and the emphasis on students' own learning rate and freedom to work at their own pace. However, the absence of indications of what constitutes a lesson could also be understood from the perspective of the Swedish empowerment culture, whereby textbooks should not steer teachers and consequently should not dictate what constitutes an appropriate unit for a lesson. Interestingly, in working with teachers, we felt they were very positive 
towards the lesson plans, frameworks, and tools introduced to make explicit their work. In other words, the contextual factor of teachers' positioning within the educational system is interpreted differently by national agencies, principals and textbook authors on the one hand, and by teachers and the research team on the other. Therefore, in the project, it was important not only to conceptualize implicit contextual factors, but also to understand how they are interpreted by different actors and navigate in this landscape to strengthen and challenge practices, tools, and contextual factors.

Cobb and Jackson (2012) theoretical framework facilitated this navigation. We as researchers constitute and are affected by current discourses and contextual factors. In Sweden, there has been a strong discourse that the development of teachers' knowledge is the most crucial factor for improving students' mathematical knowledge (Ryve et al., 2016). Here, Cobb and Jackson sensitized us to other features such as new tools, new routines, and new positions, and provided us with concepts useful in communicating about this with politicians, municipality leaders, principals, and teachers. In addition, the learning design perspective served as a highly useful perspective and frame in considering how to relate to the contextual factors in Sweden.

For instance, in new learning events, we had a strong focus on the work of teachers in classroom practices, and introduced many tools and routines that supported the teachers, as described above. Hence, the learning events, routines, tools, and missions for the new positions were directed at reorganizing the positioning of teachers in the classroom. However, both the nature of these tools and how we introduced them in learning events acknowledged the positioning of teachers within the educational system. To be clear, we appreciate the strong positioning of teachers within the educational system, but at the same time believe that research results, frameworks, and tools both could and should empower teachers to, in the case of Sweden, reorganize aspects of mathematics classroom practices and the teachers' positioning therein. Here, tools suggesting certain strategies and the rationale behind them (Kennedy, 2016) were essential in empowering teachers and suggesting ways for both teachers and students to act in classroom practices. As such, we aimed to strengthen the empowerment of teachers within the educational system by introducing tools with certain characteristics in learning events. At the same time, we aimed to challenge the positioning of teachers in the classroom through making pedagogy visible by establishing certain routines of practice and introducing frameworks and concepts enabling the teachers to represent, communicate and think about mathematical classroom practices. Finding this balance between upholding the empowerment of teachers and aiming to reorganize their roles in the classroom was essential and challenging. In such complex missions, the learning design perspective (Cobb \& Jackson, 2012) enabled us to consider and communicate about the role of teachers in improving students' mathematical knowledge, as well as to introduce a number of different ways to strengthen and challenge prevailing practices and contextual factors.

While the learning design perspective was useful, in several instances, it was not possible to follow the examples from the US context of how to design and establish new learning events, routines, positions, and tools. For instance, the missions of HMs in the project stand in rather stark contrast to the work of mathematics coaches presented in the US context. Further, since teachers individually choose their textbook series in Sweden, the tools of textbooks and teacher guides play a rather different role in Sweden than in the US context. That is, in Sweden, curriculum programs cannot function as a driving force in policy but rather as something we as researchers have to relate to. In other words, the operationalization of educational policy is context-dependent, which is our main claim in this article. 
Further, take for example Finland, a neighboring country that we have recently included in several comparative studies (e.g., Ryve et al., 2013; Hemmi \& Ryve, $2015 \mathrm{a}, 2015 \mathrm{~b})$. As to the positioning of teachers in the educational system, there is an even stronger empowerment culture in Finland than in Sweden. Finnish teachers are highly educated, and the teaching profession has a much higher status there than in Sweden. There is no school inspection, and the first national examination takes place at the end of upper secondary school. Instead, local-level monitoring and teacher-led processes are to maintain the quality of teaching and learning (e.g., Hemmi, Krzywacki, \& Partanen, 2017). In opposition to the Swedish context, teachers hold a strong position in the classroom and there is a more explicit pedagogy within the educational system (Hemmi, Krzywacki, \& Koljonen, 2017). Consequently, we conjecture that a design of a policy aimed at strengthening students' mathematics knowledge and taking into account the three aforementioned contextual factors would look very different in Finland. For instance, we would not aim to challenge the positioning of the teacher in the classroom in the same manner as we did in Sweden. Finnish teachers act proactively in the mathematics classroom (Hemmi \& Ryve, 2015a), and consequently, there are indications that they want to have control over all details concerning different students' needs and assessment (e.g., Krzywacki, Hemmi, Remillard, \& Van Steenbrugge, 2018). Moreover, concerning the visible/invisible pedagogy, Finnish teachers trust and use teacher guides, largely when planning and enacting their lessons (e.g., Hemmi, Krzywacki, \& Koljonen, 2017). During their teacher education, they learn to create quite detailed plans for lessons and for longer periods (Hemmi \& Ryve, 2015b). It is possible that certain features connected to invisible pedagogy could contribute to fruitful mathematical discussions in which students could play a more active role. In such case, Finnish teachers should learn to relinquish their control of classroom practices and leave more space for unpredictable events based on students' questions and initiatives.

To conclude, the implicit and interactive nature of the contextual factors and diverse ways to interpret them in processes of operationalizing practices and tools make it challenging to take them into consideration in designing and operationalizing educational policies. It is complex to examine and formulate specific contextual factors, understand how they could be interpreted in diverse ways, consider how to relate to them, and decide whether and how to strengthen or challenge these aspects of context. When it comes to handling contexts in large-scale studies, we suggest not only that we need to approach explicit contextual factors differently compared to small-scale studies, but also that it is essential to consider and change implicit contextual factors in establishing new learning events, new routines, new positions, and new tools. We believe that the way we conceptualized the contextual factors may help sort out essential factors and their relationships when conducting large-scale policies, not only in Sweden but in other contexts as well. The contextual factors and examples of how they affected the operationalization of the framework by Cobb and Jackson (2012) in this article, together with other frameworks such as those by Century and Cassata (2016) and McClain et al. (2009), could serve as support for scholars in considering the role of context when operationalizing theories and reorganizing practices in large-scale projects.

Open Access This article is distributed under the terms of the Creative Commons Attribution 4.0 International License (http://creativecommons.org/licenses/by/4.0/), which permits unrestricted use, distribution, and reproduction in any medium, provided you give appropriate credit to the original author(s) and the source, provide a link to the Creative Commons license, and indicate if changes were made. 


\section{References}

Ball, D. L., Sleep, L., Boerst, T., \& Bass, H. (2009). Combining the development of practice and the practice of development in teacher education. Elementary School Journal, 109(5), 458-474.

Bernstein, B. (1990). Class, codes and control, Vol. IV: The structuring of pedagogic discourse. London, UK: Routledge.

Bernstein, B. (2000). Pedagogy, symbolic control and identity: Theory, research, critique. Lanham, MD: Rowman \& Littlefield Publishers.

Blossing, U. (2008). Kompetens för samspelande skolor. [competence for collaborating schools]. Lund, Sweden: Studentlitteratur.

Boesen, J., Helenius, O., Bergqvist, E., Bergqvist, T., Lithner, J., Palm, T., \& Palmberg, B. (2014). Developing mathematical competence: From the intended to the enacted curriculum. The Journal of Mathematical Behavior, 33, 72-87.

Borko, H. (2004). Professional development and teacher learning: Mapping the terrain. Educational Researcher, 33(8), 3-15.

Brehmer, D., Ryve, A., \& Van Steenbrugge, H. (2016). Problem solving in Swedish mathematics textbooks for upper secondary school. Scandinavian Journal of Educational Research, 60(6), 577-593. https://doi. org/10.1080/00313831.2015.1066427

Brodie, K. (2011). Working with learners' mathematical thinking: Towards a language of description for changing pedagogy. Teaching and Teacher Education, 27(1), 174-186.

Bryk, A. S., Gomez, L. M., Grunow, A., \& LeMahieu, P. G. (2015). Learning to improve: How America's schools can get better at getting better. Cambridge, MA: Harvard Education Press.

Century, J., \& Cassata, A. (2016). Implementation research: Finding common ground on what, how, why, where, and who. Review of Research in Education, 40(1), 169-215.

Cobb, P., Stephan, M., McClain, K., \& Gravemeijer, K. (2001). Participating in classroom mathematical practices. Journal of the Learning Sciences, 10(1\&2), 113-163.

Cobb, P. A., \& Jackson, K. (2012). Analyzing educational policies: A learning design perspective. Journal of the Learning Sciences, 21(4), 487-521.

Coburn, C. E., \& Russell, J. L. (2008). District policy and teachers' social networks. Educational Evaluation and Policy Analysis, 30(3), 203-235.

Davis, E. A., \& Krajcik, J. S. (2005). Designing educative curriculum materials to promote teacher learning. Educational Researcher, 34(3), 3-14.

Desimone, L. M. (2009). Improving impact studies of teachers' professional development: Toward better conceptualizations and measures. Educational Researcher, 38(3), 181-199.

Feldman, M. S., \& Pentland, B. T. (2003). Reconceptualizing organizational routines as a source of flexibility and change. Administrative Science Quarterly, 48(1), 94-118.

Fowler, F. C., \& Poetter, T. S. (2004). Framing French success in elementary mathematics: Policy, curriculum, and pedagogy. Curriculum Inquiry, 34(3), 283-314.

Franke, M. L., Kazemi, E., \& Battey, D. (2007). Mathematics teaching and classroom practice. In F. K. Lester (Ed.), Second handbook of research on mathematics teaching and learning (pp. 225-256). Greenwich, CT: Information Age Publishers.

Fullan, M. (2001). The new meaning of educational change (3rd ed.). New York, NY: Teachers College Press.

Håkansson, J. (2013). Systematiskt kvalitetsarbete i förskola, skola och fritidshem: Strategier och metoder [systematic quality work in preschool, school and recreation center: Strategies and methods]. Lund: Studentlitteratur.

Hemmi, K., \& Berg, B. (2012). Empowerment and control in primary mathematics reform - The Swedish case. In C. Bergsten, E. Jablonka \& M. Raman (Eds.), Evaluation and Comparison of Mathematical Achievement: Dimensions and Perspectives: Proceedings of MADIF 8. Sweden: Umeå, January, 24-25, 2012.

Hemmi, K., Koljonen, T., Hoelgaard, L., Ahl, L., \& Ryve, A. (2014). Analyzing mathematics curriculum materials in Sweden and in Finland: Developing an analytical tool. Proceedings of the Eighth Congress of the European Society for Research in Mathematics Education (pp. 1875-1884). Ankara, Turkey: Middle East Technical University.

Hemmi, K., Krzywacki, H., \& Koljonen, T. (2017). Investigating Finnish teacher guides as a resource for mathematics teaching. Scandinavian Journal of Educational Research, 62(6), 911-928. https://doi. org/10.1080/00313831.2017.1307278

Hemmi, K., Krzywacki, H., \& Liljekvist, Y. (2018). Challenging traditional classroom practices: Swedish teachers' interplay with Finnish curriculum materials. Journal of Curriculum Studies, 1-20. Published online may 8, 2017, doi:https://doi.org/10.1080/00220272.2018.1479449 
Hemmi, K., Krzywacki, H., \& Partanen, A.-M. (2017). Mathematics curriculum: The case of Finland. In C. Suurtam et al. (Eds.), International perspectives on mathematics curriculum (pp. 71-102). Charlotte, NC: Information Age Publishing.

Hemmi, K., Lepik, M., \& Viholainen, A. (2013). Analysing proof-related competences in Estonian, Finnish and Swedish mathematics curricula: Towards a framework of developmental proof. Journal of Curriculum Studies, 45(3), 354-378.

Hemmi, K., \& Ryve, A. (2015a). Effective mathematics teaching in Finnish and Swedish teacher education discourses. Journal of Mathematics Teacher Education, 18(6), 501-521.

Hemmi, K., \& Ryve, A. (2015b). The culture of the mathematics classroom during the first school years in Finland and Sweden. In B. Perry, A. MacDonald, \& A. Gervasoni (Eds.), Mathematics and transition to school: International perspectives (pp. 185-198). Singapore: Springer.

Kazemi, E., \& Franke, M. L. (2004). Teacher learning in mathematics: Using student work to promote collective inquiry. Journal of Mathematics Teacher Education, 7(3), 203-235.

Kennedy, M. M. (2016). How does professional development improve teaching? Review of Educational Research, 86(4), 945-980. https://doi.org/10.3102/0034654315626800

Kilpatrick, J., Swafford, J., \& Findell, B. (Eds.). (2001). Adding it up: Helping children learn mathematics. Washington, DC: National Academies Press.

Kornhall, P. (2015). Förstelärare: en metodbok [First teacher: A handbook]. Stockholm: Natur \& Kultur.

Krzywacki, H., Hemmi, K., Remillard, J., \& Van Steenbrugge, H. (2018). Finnish primary teachers' interaction with curriculum materials: Digitalisation as an augmenting element. In E. Bergqvist, M. Österholm, C. Granberg, \& L. Sumpter (Eds.), Proceedings of the 42nd Conference of the International Group for the Psychology of Mathematics Education (pp. 259-266). Umeå, Sweden: PME.

Lindvall, J. (2017a). Large-scale professional development and its impact on mathematics instruction: Differences between primary and secondary grades. In J. Häggström, E. Norén, J. van Bommel, J. Sayers, O. Helenius, \& Y. Liljekvist (Eds.), ICT in mathematics education: The future and the realities. Proceedings of MADIF10. The tenth research seminar of the Swedish Society for Research in Mathematics Education (pp. 57-66). SMDF/NCM: Gothenburg, Sweden.

Lindvall, J. (2017b). Two large-scale professional development programs for mathematics teachers and their impact on student achievement. International Journal of Science and Mathematics Education, 15(7), 12811301.

Lindvall, J., Helenius, O., \& Wiberg, M. (2018). Critical features of professional development programs: Comparing content focus and impact of two large-scale programs. Teaching and Teacher Education, 70, $121-131$.

Lloyd, G., Remillard, J. T., \& Herbel-Eisenmann, B. (2009). Teachers' use of curriculum materials: An emerging field. In J. T. Remillard, B. Herbel-Eisenmann, \& G. Lloyd (Eds.), Mathematics teachers at work: Connecting curriculum materials and classroom instruction (pp. 3-14). NY: Routledge.

McClain, K., Zhao, Q., Visnovska, K., \& Bowen, E. (2009). Understanding the role of the institutional context in the relationship between teachers and text. In J. T. Remillard, B. Herbel-Eisenmann, \& G. Lloyd (Eds.), Mathematics teachers at work: Connecting curriculum materials and classroom instruction (pp. 37-55). NY: Routledge.

McKenney, S., \& Reeves, T. C. (2012). Conducting educational research design. London: Routledge.

Neuman (Lindvall), J., Hemmi, K., Ryve, A., \& Wiberg, M. (2015). Mathematics textbooks' impact on classroom instruction: Examining the views of 278 Swedish teachers. In H. Silfverberg, T. Kärki, \& M.S. Hannula (Eds.), Nordic research in mathematics education - Proceedings of NORMA14, Turku, June 3-6, 2014 (pp. 215-225). Turku, Finland: The Finnish Research Association for Subject Didactics.

Porter, A. C., Archbald, D. A., \& Tyree, A. K., Jr. (1990). Reforming the curriculum: Will empowerment policies replace control? In S. Fuhrman \& B. Malen (Eds.), The politics of curriculum and testing: The 1990 yearbook of the Politics of Education Associations (pp. 11-36). London: Taylor \& Francis Ltd..

Remillard, J. (2005). Examining key concepts in research on teachers' use of mathematics curricula. Review of Educational Research, 75(2), 211-246.

Remillard, J., Van Steenbrugge, H., \& Bergqvist, T. (2014). A cross-cultural analysis of the voice of curriculum materials. In K. Jones, C. Bokhove, G. Howson, \& L. Fan (Eds.), Proceedings of the International Conference on Mathematics Textbook Research and Development (ICMT-2014) (pp. 395-400). Southampton: University of Southampton.

Remillard, J. T. (2000). Can curriculum materials support teachers' learning? Two fourth-grade teachers' use of a new mathematics text. Elementary School Journal, 100(4), 331-350.

Ruthven, K., Laborde, C., Leach, J., \& Tiberghien, A. (2009). Design tools in didactical research: Instrumenting the epistemological and cognitive aspects of the design of teaching sequences. Educational Researcher, 38(5), 329-342. 
Ryve, A., Hemmi, K., \& Börjesson, M. (2013). Discourses about school-based mathematics teacher education in Finland and Sweden. Scandinavian Journal of Educational Research, 57(2), 132-147.

Ryve, A., Hemmi, K., \& Kornhall, P. (2016). Skola på vetenskaplig grund [School on a scientific basis]. Stockholm: Natur \& Kultur.

Smith, M. S., \& Stein, M. K. (2011). 5 practices for orchestrating productive mathematics discussions. Reston, VA: National Council of Teachers of Mathematics.

Van Steenbrugge, H., \& Ryve, A. (2018). Developing a reform mathematics curriculum program in Sweden: Relating international research and the local context. ZDM Mathematics Education, 50(5), 801-812. https://doi.org/10.1007/s11858-018-0972-y

Wertsch, J. V. (2007). Mediation. In H. Daniels, M. Cole, \& J. V. Wertsch (Eds.), The Cambridge companion to Vygotsky (pp. 178-192). Cambridge: Cambridge University Press.

Publisher's note Springer Nature remains neutral with regard to jurisdictional claims in published maps and institutional affiliations. 